\title{
The Influence of the Topology of Test Circuits on the Interrupting Performance of Circuit Breakers
}

\author{
P.H. Schavemaker, Non-Member IEEE L. van der Sluis, Senior Member IEEE \\ Delft University of Technology, Faculty of Electrical Engineering, Power Systems Laboratory, \\ Mekelweg 4, 2628 CD DELFT, the Netherlands
}

\begin{abstract}
High-voltage circuit breakers are tested in the High Power Laboratory where transient recovery voltages (TRVs) are generated by networks consisting of lumped elements. In the IEC and ANSI standards the TRV waveforms are described, but not the topology of the test circuits. This paper compares different direct TRV test circuits which generate the same initial part of the TRV waveform. It is demonstrated that the surge impedance of the TRV test circuit is an important parameter. The difference in interrupting performance of the TB in the test circuits with the different surge impedances is caused by the influence of the arc-circuit interaction.
\end{abstract}

\section{Keywords:}

circuit breaker, arc models, arc-circuit interaction, IEC standard, transient recovery voltage, test circuits

\section{INTRODUCTION}

High-voltage circuit breakers are the main protective devices in electrical transmission and distribution networks. They must clear faults and isolate faulted sections. Since they are protective devices, they must be reliable in their operation and be able to clear a wide range of load and fault currents. The testing of high-voltage circuit breakers is done in the High Power Laboratory.

The transient recovery voltage (TRV) is the voltage that builds up across a circuit breaker after the interruption of a fault current. The TRV consists of oscillations of lumped elements and of travelling waves. The TRV which stresses a breaker depends on the type of fault, the location of the fault and the type of circuit switched. The TRV waveforms are standardized for a limited number of faults. These TRV parameters can be found in the IEC and ANSI standards. The TRV parameters and waveform of the IEC-56 are considered in this paper.

95 WT 009-1 PWRD A paper recommended and approved by the IEEE Switchgear Committee of the IEEE Power Engineering Society for presentation at the 199 IFEE/PES Winter Meeting, January 29, to February 2, 1995. New York, NY. Manuscript submitted July 22, 1994; made available for printing December 6, 1994.
The parameters of the prospective TRV waveform are given in the IEC-56 standard [1]. The prospective TRV is the voltage that builds up across an ideal circuit breaker. This means that the influence of the circuit breaker arc is neglected. The prospective TRV is described by the voltage waveform only. No guidance is given on how to realise the TRV waveform, and this presents the possibility to create test circuits, with different topology, which generate the same prospective TRV.

This paper gives the results of simulations to enable study as to whether there is a difference in the interrupting performance of circuit breakers caused by the difference in the topology of the test circuits, when the influence of the arc voltage is considered.

The test breaker (TB) is an $\mathrm{SF}_{6}$ circuit breaker with a short circuit rating of $123 \mathrm{kV}-20 \mathrm{kA}-50 \mathrm{~Hz}$.

A good arc model is a necessary tool to simulate the behavior of the TB in a computer program. The KEMA arc model, with parameters derived from real tests, has been used in several computer simulations with good results $[2,3]$. The KEMA arc model with parameters for an $123 \mathrm{kV}-20 \mathrm{kA}-50 \mathrm{~Hz}$ $\mathrm{SF}_{6}$ breaker is used for the computations reported in this paper.

The KEMA arc model is a hybrid model $[2,4,5]$. Before current zero, the arc conductance is calculated from the energy balance between the power loss and the power input in the arc channel with the modified Mayr model. After current zero, the arc conductance is calculated from the decay of charged particles by diffusion, recombination and attachment with the recombination model.

The calculations were made with two different programs: a transient program developed at the Power Systems Laboratory of the Delft University of Technology, and the computations were checked with ACSL (Advanced Continuous Simulation Language), a program for the solution of a set of differential equations. 
THE SIMULATIONS

Calculations were performed with TBs inserted in direct test circuits with different topology and with different surge impedances. The time delay, typically $2 \mu \mathrm{s}$, gives the extra degree of freedom to create test circuits which have an identical initial prospective TRV waveform but are different in surge impedance. The test circuits used in this paper are shown in the appendix (fig. A1 to A8).

The test circuits TRVxC (fig. A1/A2/A3/A4) are direct test circuits with a rated surge impedance $\mathrm{Z}=225.2 \Omega$ and a time delay capacitor $\mathrm{C}_{\mathrm{d}}=8.88 \mathrm{nF}$, generating an identical waveshape in the first twenty microseconds. The parameters of these circuits were chosen such that the IEC requirement with respect to the rate of rise of the TRV $\left(\mathrm{U}_{1} / \mathrm{t}_{1}\right)$ is fulfilled, as shown in fig. 1 in the case of test circuit TRV2C.

The test circuits TRVxR (fig. A5/A6/A7/A8) are direct test circuits with a lower surge impedance $Z=150 \Omega$ and without a time delay capacitor, generating the same prospective TRV in the first twenty microseconds. The parameters of these circuits were chosen such that the prospective TRV in the first twenty microseconds is slightly higher than the prospective TRV of the circuits TRVxC, as shown in fig. 2 in the case of test circuit TRV2R.

The rated surge impedance value is calculated with $\mathrm{Z}=(\mathrm{du} / \mathrm{dt}) /(\mathrm{di} / \mathrm{dt})$. The $\mathrm{du} / \mathrm{dt}$ and $\mathrm{di} / \mathrm{dt}$ are the rate of rise of the recovery voltage and short circuit current at current zero respectively. Fig. 2 shows that the initial slope of the prospective TRVs is not dominated by the surge impedance only, but is also influenced by the lumped L's and C's.

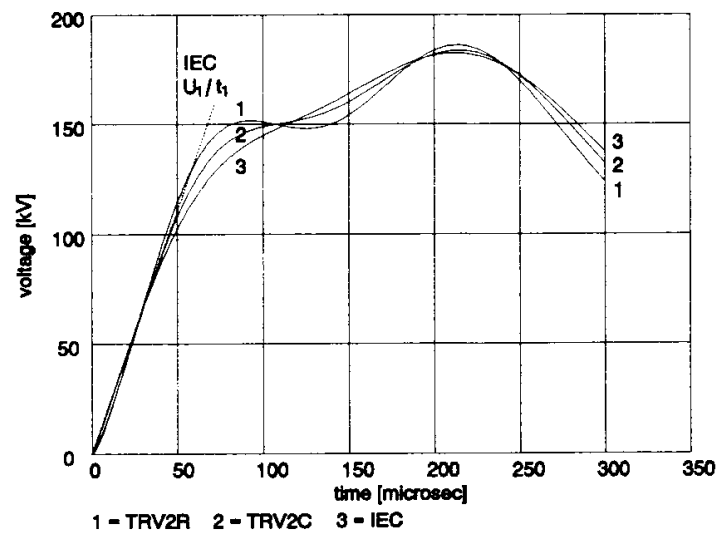

Fig. 1. The relation between the IEC and the prospective TRVs

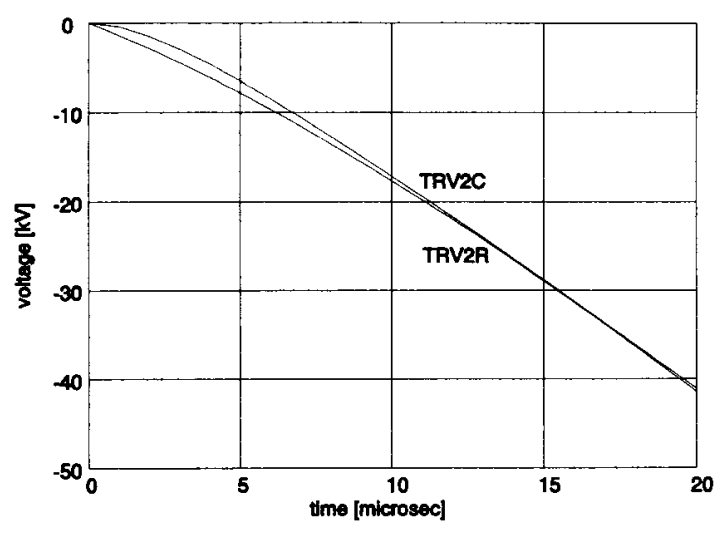

Fig. 2. Initial slope of the prospective TRVs

The TRV waveform labeled number 3 in fig. 1 is a prospective TRV without a time delay produced by a TRV2-type test circuit with a rated surge impedance of $225 \Omega$. This prospective TRV is in accordance with the IEC four parameter envelope and is shown in fig. 1 in comparison with the other TRV waveforms.

As can be seen from fig. 1 and fig. 2, the test circuits TRVxR could put more stress on the TB than the test circuits TRVxC, because the rate of rise of the voltage waveform is higher.

The $\mathrm{SF}_{6}$ pressure of the arc model is used as a variable parameter to compare the interrupting performance of the arc model in the eight different test circuits. The gas pressure was varied till the arc model was just able to clear the short circuit current without a thermal reignition. The computed clearing pressures and arc resistances at current zero are shown in table 1 . The higher the gas pressure is, the more difficult it is for the TB to clear.

The difference in the calculated clearing pressures of the $T B$, inserted in the test circuits with different topology but with equal surge impedance (TRVXC or TRVxR) is less than one percent.

The difference in the calculated clearing pressures of the TB, inserted in the test circuits with the rated (TRVxC) and the lower (TRVxR) surge impedance is almost four percent. Therefore it can be concluded that the test circuits TRVxC stress the TB more than the test circuits TRVxR, in spite of the fact that the initial prospective TRV waveforms of the circuits TRVxC are lower than those of TRVXR. 
Table 1. Computed clearing pressures and arc resistances at current zero of the TB in the eight test circuits.

\begin{tabular}{||c|c|c||}
\hline circuit & $\begin{array}{c}\text { clearing } \\
\text { pressure } \\
\text { [bar] }\end{array}$ & $\begin{array}{c}\text { arc resistance } \\
\text { at current zero } \\
{[\Omega]}\end{array}$ \\
\hline \hline TRV1C & 5.23 & 216 \\
\hline TRV1R & 5.06 & 166 \\
\hline TRV2C & 5.26 & 215 \\
\hline TRV2R & 5.06 & 166 \\
\hline TRV3C & 5.23 & 216 \\
\hline TRV3R & 5.07 & 168 \\
\hline TRV4C & 5.22 & 215 \\
\hline TRV4R & 5.03 & 165 \\
\hline
\end{tabular}

The difference in interrupting performance of the TB in the test circuits with the different surge impedances is caused by the arc-circuit interaction. In the following, the arc-circuit interaction in the test circuits TRV2C and TRV2R (fig. A2 and fig. A6 respectively) is analyzed.

\section{ARC-CIRCUIT INTERACTION BEFORE CURRENT ZERO}

In the high current interval, the capacitors $C_{1}$ and $\mathrm{C}_{2}$ are charged and have a voltage almost equal to the steady state arc voltage. Before current zero, the voltage supplied to the circuit can be considered to have a constant value $\hat{E}$. Therefore, the $\mathrm{di} / \mathrm{dt}$ of the current through the short circuit inductance $L_{0}$ remains constant if the source driving voltage is considerable higher than the arc voltage $\left(\hat{E} \gg U_{\text {arc }}\right)$ (1).

$$
\frac{d i}{d t}=\frac{\hat{E}-U_{\text {arc }}}{L_{0}}
$$

As a result of the decrease of the arc voltage just before current zero, the capacitor $\mathrm{C}_{1}$, charged during the high current interval, will discharge. At current zero, the current through the inductance $\mathrm{L}_{0}$ is equal to the current discharging the capacitor $\mathrm{C}_{1}$. In a manner of speaking, the current is withdrawn from the arc and this entails a lower power input into the arc channel just before current zero. The consequence is an arc channel with a higher resistance at current zero, compared with the situation without arc voltage.

In the case of test circuit TRV2C, the time delay capacitor $\mathrm{C}_{\mathrm{d}}$ contributes to the arc-circuit interaction too. Just before current zero, the arc voltage goes to zero with a steep $\mathrm{dU}_{\text {arc }} / \mathrm{dt}$, resulting in a capacitive current:

$$
i_{c}=C_{d} \cdot \frac{d U_{\mathrm{arc}}}{d t}
$$

At current zero, the current through the inductance $\mathrm{L}_{0}$ is equal to the sum of the discharging currents from capacitor $C_{1}$ and the time delay capacitor $C_{d}$. This entails an even higher arc resistance at current zero, compared with test circuit TRV2R.

The arc-circuit interaction before current zero entails a circuit with energy stored in the capacitors and in the inductors at current zero. The amount of energy stored in the circuit elements is different for the two test circuits. At current zero, a higher current flows through - and more energy is stored in - the inductance $\mathrm{L}_{0}$ in the test circuit TRV2C than in the test circuit TRV2R. The energy stored in the circuit elements at current zero influences the interrupting performance of the TB.

\section{ARC-CIRCUIT INTERACTION AFTER CURRENT ZERO}

The damping of the TRV waveform caused by the (non-infinite) arc resistance is not significant because of the fast rise of the arc resistance. This is confirmed by the following simulations.

The KEMA arc model is used to simulate the TB both before current zero and after current zero. The influence of the arc channel resistance after current zero can be studied by the comparison of the TRV waveforms, produced by the "arc-circuit interaction" (calculated with the KEMA arc model) and the "non-arc-circuit interaction" (calculated with the modified Mayr arc model before current zero and an infinite arc channel resistance after current zero). These calculations have been performed for the test circuits TRV2C and TRV2R. Fig. 3 shows the four calculated TRV waveforms.

It can be seen that there is hardly any difference in the TRV waveforms caused by the difference in arc resistance after current zero. In other words: the "arc-circuit interaction" after current zero is negligible. Thus the different stresses on the TB in the different circuits are caused by the arc-circuit interaction just before current zero. The energy stored in the circuit elements at current zero is an effect of the arc-circuit interaction before current zero and is the important factor that determines the stress of a test circuit on the TB. 


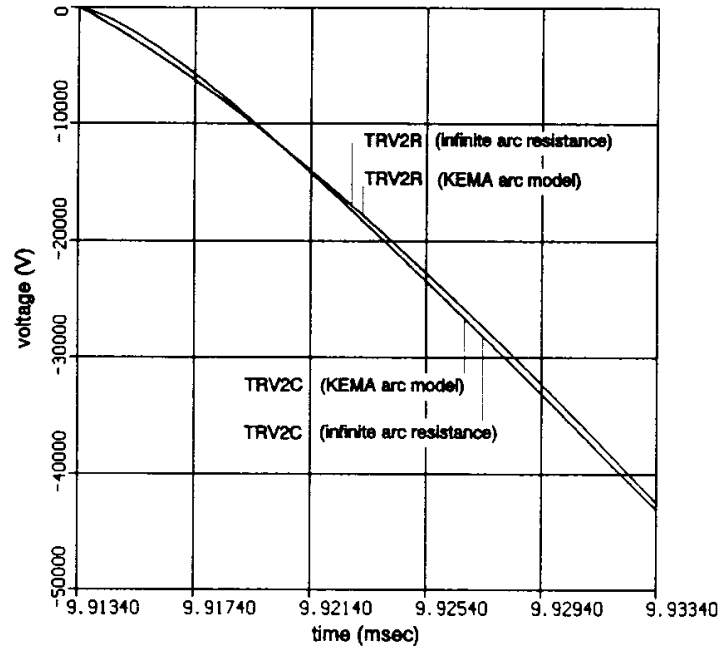

Fig. 3. Initial TRVs calculated with and without damping after current zero

THE INFLUENCE OF THE ENERGY STORED IN THE TEST CIRCUIT AT CURRENT ZERO

The arc-circuit interaction before current zero entails a circuit with energy stored in the capacitors and in the inductors at current zero. The energy stored in the circuit elements has a strong influence on the interrupting performance of the TB.

Because the influence of the non-infinite arc resistance on the TRV is not significant, the TRV waveform can be considered as a superposition of the prospective TRV and the transient response of the circuit caused by the energy stored in the circuit at current zero as shown in fig. 4.

The initial prospective TRVs of the two test circuits are shown in fig. 2. The transient responses of the two test circuits, caused by the energy stored in the circuit at current zero, are different (fig. 5). These differences result in different initial TRVs (fig. 6) and different stresses on the TB.
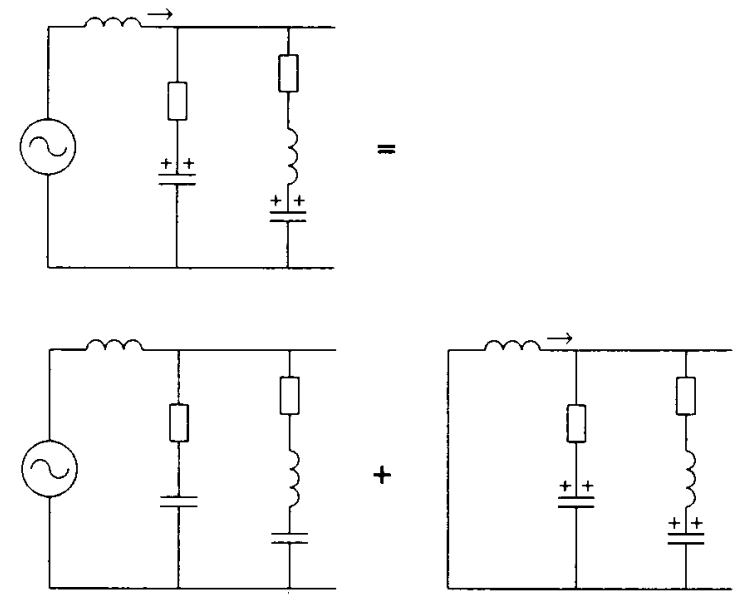

Fig. 4. Superposition principle

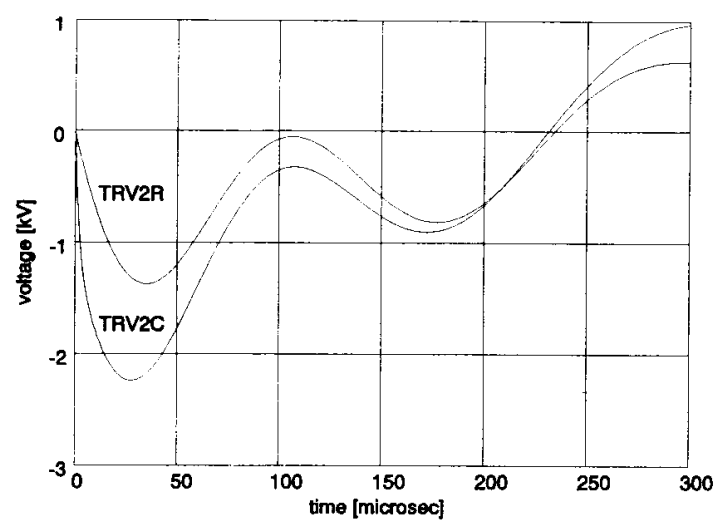

Fig. 5. Transient responses of the test circuits caused by the energy stored in the circuit at current zero

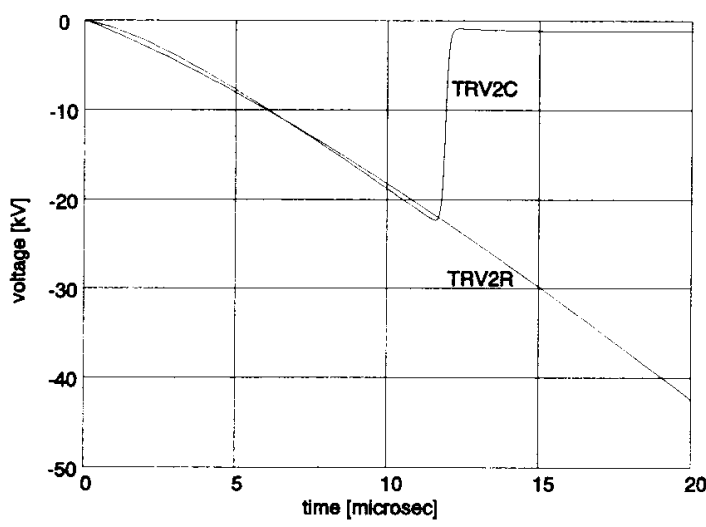

Fig. 6. The initial TRVs caused by the arc-circuit interaction

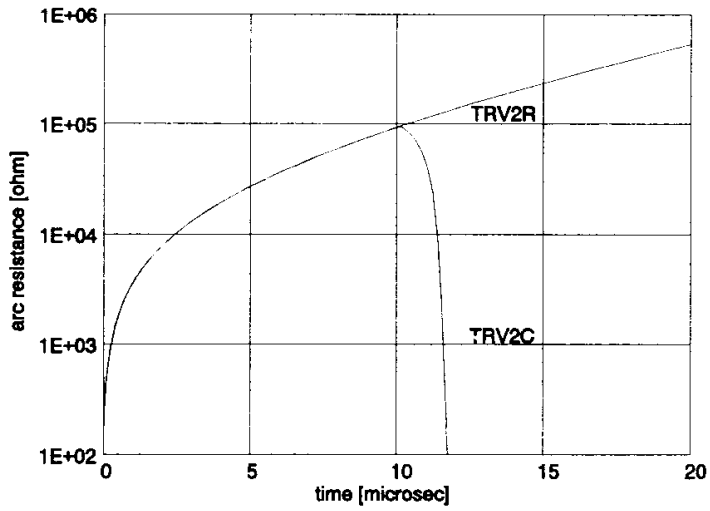

Fig. 7. Arc resistances in the test circuits TRV2C and TRV2R

For both the circuits, TRV2C and TRV2R, the $\mathrm{SF}_{6}$ pressure in the calculations was $\mathrm{P}=5.06$ bar. Because of the arc-circuit interaction, the TRV2C circuit puts more stress on the TB than the TRV2R circuit, in spite of the fact that the initial prospective 
TRV of circuit TRV2R is higher than the initial prospective TRV of circuit TRV2C, as can be seen in fig. 2. Calculations show that the TB reignites $10 \mu \mathrm{s}$ after current zero in the TRV2C circuit but clears succesfully in the TRV2R circuit, as can be seen in fig. 6 and fig. 7. The reignition of the breaker in the TRV2C circuit is caused by the thermal breakdown of the arc-channel as calculated with the arc model $[2,3,4,5]$.

The energy stored in the lumped elements at current zero has a dominating influence on the initial TRV and causes the difference in stress on the TB in the two test circuits. The arc voltage influences the energy stored in the test circuit at current zero because of the arc-circuit interaction. The influence of the shape of the arc voltage is examined hereunder.

\section{THE INFLUENCE OF THE SHAPE OF THE ARC VOLTAGE}

The shape of the arc voltage waveform depends on the interrupter design. The arc voltage influences the amount of energy stored in the capacitors and in the inductors in the test circuit at current zero because of the arc-circuit interaction. The energy stored in the circuit elements at current zero affects the initial TRV and gives a different stress on the TB.

As previously concluded, the TRV2C circuit puts more stress on the TB than the TRV2R circuit when the arc has a flat arc voltage waveform (curve 1 in fig. 8). Here we examine whether the same conclusion is valid when the arc voltage has an extinguishing peak (curve 3 in fig. 8) and a nonsignificant extinguishing peak (curve 2 in fig. 8). The different arc voltage waveforms, as shown in fig. 8 , can be created with the KEMA arc model with the parameters from table 2 for the modified Mayr model (3).

$$
\frac{1}{G} \frac{d G}{d t}=\frac{1}{\tau}\left[\frac{I U}{P\left(P_{0}+C_{l}|I|\right)}-1\right]
$$

$$
\begin{array}{llll}
\mathrm{P} & \mathrm{SF}_{6} \text { pressure } & \mathrm{U} & \text { arc voltage } \\
\mathrm{G} & \text { arc conductance } & \mathrm{I} & \text { arc current } \\
\mathrm{P}_{0} & \text { cooling power } & \tau & \text { time constant } \\
\mathrm{C}_{1} & \text { current constant } & &
\end{array}
$$

The clearing pressure of the TB in test circuit TRV2C is used as a reference to compare the clearing pressures of the TB in the various test circuits with the different arc voltage waveforms.
The test circuits TRVXC put more stress on the TB than the test circuits $T R V x R$, in spite of the fact that the initial prospective TRVs of the test circuits TRVXC are lower than those of TRVxR. It can be seen from table 3 that the higher the extinguishing peak of the arc voltage the larger the difference between the clearing pressures of the TB in the test circuits TRVXC and TRVXR.

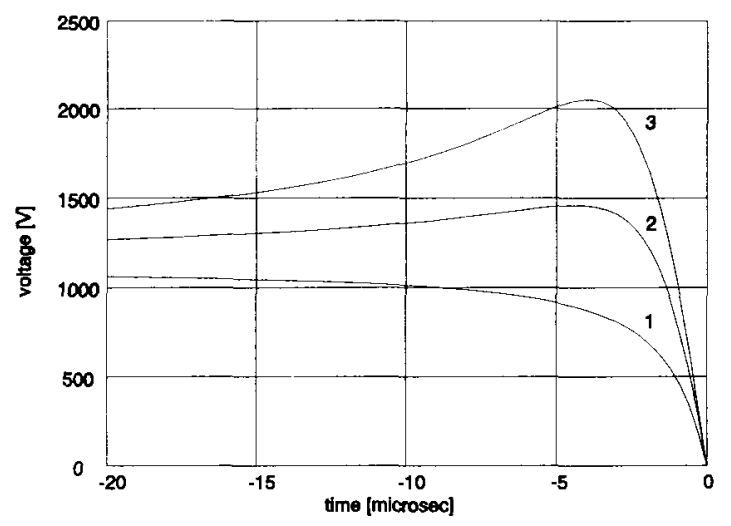

Fig. 8. Three different arc voltage waveforms

Table 2. Arc model parameters for the three different arc voltage waveforms

\begin{tabular}{||c|c|c|c||}
\hline arc voltage & $\begin{array}{c}\mathrm{P}_{0} \\
{[\mathrm{~W} / \mathrm{bar}]}\end{array}$ & $\begin{array}{c}\mathrm{C}_{\mathrm{I}} \\
{[\mathrm{V} / \mathrm{bar}]}\end{array}$ & $\begin{array}{c}\tau \\
{[\mu \mathrm{s}]}\end{array}$ \\
\hline \hline type 1 & 500 & 220 & 1.2 \\
\hline type 2 & 6500 & 220 & 1.2 \\
\hline type 3 & 12500 & 220 & 1.2 \\
\hline
\end{tabular}

Table 3. Computed clearing pressures of the TB in the eight test circuits caused by the three different arc voltage waveforms.

\begin{tabular}{||c|c|c|c||}
\hline circuit & $\begin{array}{c}\text { arc model } \\
\text { type 1 }\end{array}$ & $\begin{array}{c}\text { arc model } \\
\text { type 2 }\end{array}$ & $\begin{array}{c}\text { arc model } \\
\text { type 3 }\end{array}$ \\
\hline \hline TRV1C & 5.23 & 5.27 & 5.25 \\
\hline TRV1R & 5.06 & 4.96 & 4.90 \\
\hline TRV2C & 5.26 & 5.26 & 5.26 \\
\hline TRV2R & 5.06 & 4.97 & 4.91 \\
\hline TRV3C & 5.23 & 5.26 & 5.21 \\
\hline TRV3R & 5.07 & 4.97 & 4.92 \\
\hline TRV4C & 5.22 & 5.25 & 5.19 \\
\hline TRV4R & 5.03 & 4.94 & 4.89 \\
\hline
\end{tabular}




\section{CONCLUSIONS}

Calculations were performed with TBs inserted in direct test circuits with different topology and with different surge impedances which generate the same initial prospective TRV waveform. The time delay gives the extra degree of freedom to create test circuits which have an identical initial prospective TRV waveform but differ in surge impedance.

The calculations show that the difference in clearing pressure, caused by the different topology of the test circuits is less than one percent.

The calculations also show that the difference in clearing pressure, caused by the difference in surge impedance is almost four percent. Calculations with arc models creating different arc voltage waveforms show that the higher the extinguishing peak of the arc voltage the larger the difference between the clearing pressures of the TB in the test circuits with different surge impedance.

As a result of these simulations, the requirements for test circuits should be:

- test circuits must generate a prospective TRV according to the IEC (or ANSI) standard;

- test circuits must have the rated surge impedance at current zero;

- test circuits, generating a prospective TRV with a time delay, must have the rated surge impedance and a time delay capacitor parallel to the breaker.

The difference in interrupting performance of the TB in the test circuits with the different surge impedances is caused by the arc-circuit interaction.

The arc-circuit interaction before current zero entails a circuit with energy stored in the capacitors and in the inductors at current zero. The energy stored in the circuit elements at current zero has a strong influence on the interrupting performance of the TB.

Since the influence of the non-infinite arc resistance on the TRV is not significant, the TRV waveform can be considered as a superposition of the prospective TRV and the transient response of the circuit caused by the energy stored in the circuit at current zero. The transient responses of the test circuits with different surge impedance, caused by the energy stored in the circuit at current zero, are different. These differences result in different initial TRVs and different stresses on the TB.

\section{REFERENCES}

[1] IEC-56, 1987.

[2] L. van der Sluis and W.R. Rutgers: "Comparison of test circuits for high-voltage circuit breakers by numerical calculations with arc models", IEEE Transactions on Power Delivery, Vol. 7, No. 4, pp. 2037-2045, Oct. 1992.

[3] L. van der Sluis, W.R. Rutgers and G.C. Damstra: "The calculation of arc-circuit interaction of high-voltage circuit breakers", paper presented at the 1993 IEEE/NTUA Athens Power Tech Conference, Vol. I, pp. 126-131, Greece, Sept. 5-8, 1993.

[4] L. van der Sluis, W.R. Rutgers and C.G.A. Koreman: "A physical arc model for the simulation of current zero behavior of highvoltage circuit breakers", IEEE Transactions on Power Delivery, Vol. 7, No. 2, pp. 1016-1022, April 1992.

[5] W.R. Rutgers and L. van der Sluis: "Modelling of switching arcs during high-current interruption", Proceedings of the $10^{\text {h }}$ Conf. on Gas discharges and their applications, Vol. I, pp. 6-9, Swansea 1992.

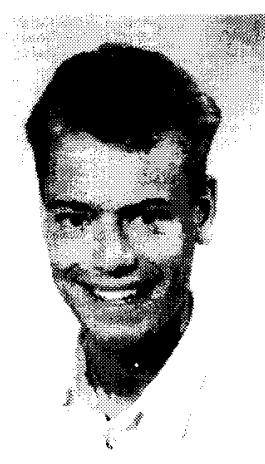

Pieter H. Schavemaker was born in Velsen, the Netherlands on November 30, 1970. He obtained his M.Sc. in Electrical Engineering from the Delft University of Technology in 1994. Since then he has been with the Power System Laboratory of the same university where he is working towards his Ph.D.

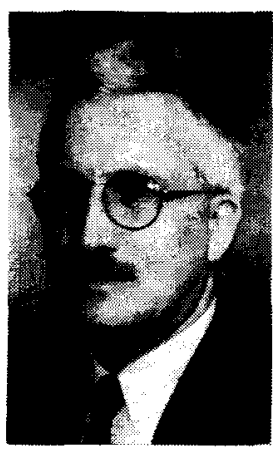

Lou van der Sluis was born in Geervliet, the Netherlands on July 10 , 1950. He obtained his M.Sc. in Electrical Engineering from the Delft University of Technology in 1974. He joined KEMA's High Power Laboratory in 1977 as a test engineer and was involved in the development of a data acquisition system for the High Power Laboratory, computer calculations of test circuits and analysis of test data by digital computer. In 1990 he became a part-time professor and since 1992 he has been employed as a full-time professor at the Delft University of Technology in the Power System Department. Prof. van der Sluis is a senior member of IEEE and convener of WG 13-07 of CIGRE to study the transient recovery voltages in medium- and high-voltage networks. 


\section{APPENDIX}

The test circuits TRVXC shown in fig. A1/A2/A3/A4 are direct test circuits with a rated surge impedance $\mathrm{Z}=225.2 \Omega$ and a time delay capacitor $C_{d}=8.88 n F$, generating the same initial prospective TRV.

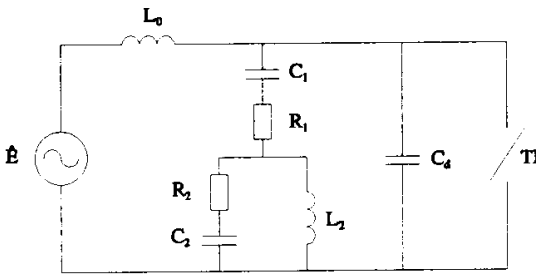

$\hat{\mathrm{E}}=138 \mathrm{kV}$

$\mathrm{L}_{0}=15.54 \mathrm{mH}$

$\mathrm{L}_{2}=3.2 \mathrm{mH}$

$\mathrm{C}_{1}=0.15 \mu \mathrm{F}$

B $\mathrm{C}_{2}=0.315 \mu \mathrm{F}$

$\mathrm{C}_{\mathrm{d}}=8.88 \mathrm{nF}$

$\mathrm{R}_{1}=192.2 \Omega$

$\mathrm{R}_{2}=33 \Omega$

Fig. A1. Test circuit TRV1C

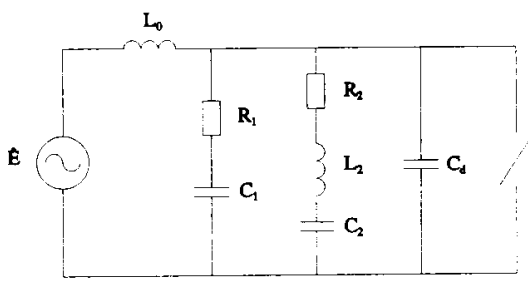

$\hat{\mathrm{E}}=131 \mathrm{kV}$

$\mathrm{L}_{0}=14.75 \mathrm{mH}$

$\mathrm{L}_{2}=27.8 \mathrm{mH}$

$\mathrm{C}_{1}=0.083 \mu \mathrm{F}$

TB $\mathrm{C}_{2}=0.084 \mu \mathrm{F}$

$\mathrm{C}_{\mathrm{d}}=8.88 \mathrm{nF}$

$\mathrm{R}_{1}=225.2 \mathrm{\Omega}$

$\mathrm{R}_{2}=112.6 \Omega$

Fig. A2. Test circuit TRV2C

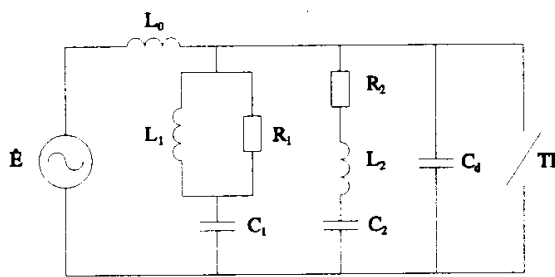

Fig. A3. Test circuit TRV3C

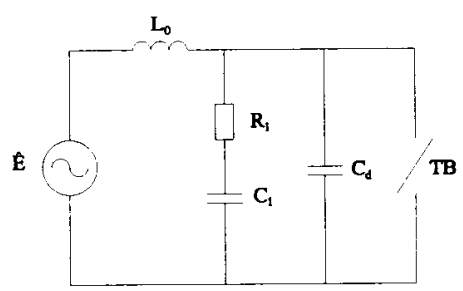

$\hat{\mathrm{E}}=131 \mathrm{kV}$

$\mathrm{L}_{0}=14.75 \mathrm{mH}$

$\mathrm{C}_{1}=0.11 \mu \mathrm{F}$

$\mathrm{C}_{\mathrm{d}}=8.88 \mathrm{nF}$

$\mathrm{R}_{1}=225.2 \Omega$
$\hat{\mathrm{E}}=133 \mathrm{kV}$

$\mathrm{L}_{0}=14.98 \mathrm{mH}$

$\mathrm{L}_{1}=9.85 \mathrm{mH}$

$\mathrm{L}_{2}=17 \mathrm{mH}$

$\mathrm{C}_{1}=0.055 \mu \mathrm{F}$

$\mathrm{C}_{2}=0.14 \mu \mathrm{F}$

$\mathrm{C}_{\mathrm{d}}=8.88 \mathrm{nF}$

$\mathrm{R}_{1}=225.2 \Omega$

$\mathrm{R}_{2}=185 \Omega$

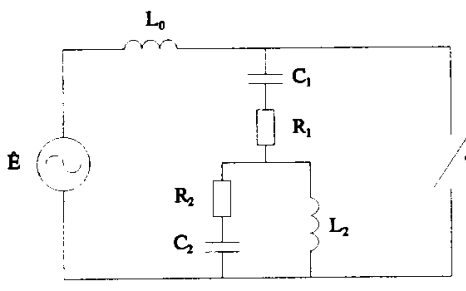

Fig. A5. Test circuit TRV1R
$\hat{\mathrm{E}}=138 \mathrm{kV}$

$\mathrm{L}_{0}=15.54 \mathrm{mH}$

$\mathrm{L}_{2}=3.2 \mathrm{mH}$

TB $\mathrm{C}_{1}=0.11 \mu \mathrm{F}$

$\mathrm{C}_{2}=0.315 \mu \mathrm{F}$

$\mathrm{R}_{1}=117 \Omega$

$\mathrm{R}_{2}=33 \Omega$

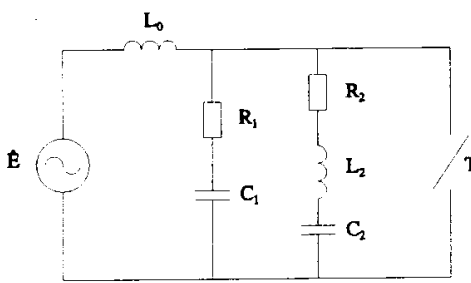

Fig. A6. Test circuit TRV2R
$\hat{\mathrm{E}}=131 \mathrm{kV}$

$\mathrm{L}_{0}=14.75 \mathrm{mH}$

$\mathrm{L}_{2}=27.8 \mathrm{mH}$

TB $\mathrm{C}_{1}=0.075 \mu \mathrm{F}$

$\mathrm{C}_{2}=0.084 \mu \mathrm{F}$

$\mathrm{R}_{1}=150 \Omega$

$\mathrm{R}_{2}=112.6 \Omega$

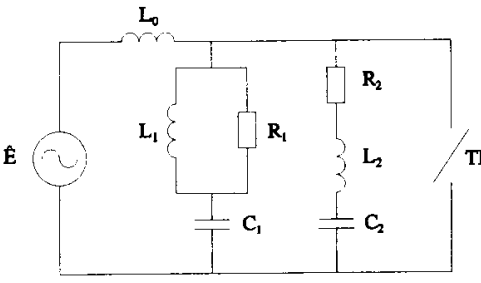

Fig. A7. Test circuit TRV3R
$\hat{\mathrm{E}}=133 \mathrm{kV}$

$\mathrm{L}_{0}=14.98 \mathrm{mH}$

$\mathrm{L}_{1}=9.85 \mathrm{mH}$

$\mathrm{L}_{2}=17 \mathrm{mH}$

TB $\mathrm{C}_{1}=0.061 \mu \mathrm{F}$

$\mathrm{C}_{2}=0.14 \mu \mathrm{F}$

$R_{1}=150 \Omega$

$R_{2}=185 \Omega$

Fig. A4. Test circuit TRV4C

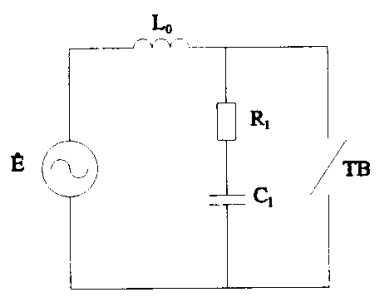

Fig. A8. Test circuit TRV4R
$\hat{\mathrm{E}}=131 \mathrm{kV}$

$\mathrm{L}_{0}=14.75 \mathrm{mH}$

$\mathrm{C}_{1}=0.087 \mu \mathrm{F}$

$\mathrm{R}_{1}=150 \Omega$ 